\title{
Robust impact design of steel and composite building structures: The Alternate Load Path Approach
}

\author{
Nadine HOFFMANN \\ Scientific Researcher \\ University of Stuttgart \\ Stuttgart , Germany \\ nadine.hoffmann@ke.uni- \\ stuttgart.de
}

Jean-Pierre JASPART

Professor

University of Liège

Liège, Belgium

jean-pierre.jaspart@ulg.ac.be

\author{
Ulrike KUHLMANN \\ Professor \\ University of Stuttgart \\ Stuttgart, Germany \\ u.kuhlmann@ke.uni-stuttgart.de
}

Nadia BALDASSINO
Assistant professor
University of Trento
Trento, Italy
nadia.baldassino@unitn.it

\author{
Jean-François \\ DEMONCEAU \\ Associate Professor \\ University of Liège \\ Liège, Belgium \\ jfdemonceau@ulg.ac.be
}

\section{Fabio FREDDI}

Postdoctoral research fellow

University of Trento

Trento, Italy

fabio.freddi@unitn.it

Riccardo ZANDONINI

Professor

University of Trento

Trento, Italy

riccardo.zandonini@unitn.it

\section{Summary}

Vulnerability of structures to progressive collapse and mitigation of the effects of local damages are topics widely discussed. The studies worldwide carried out allowed identifying different design strategies. However, specific knowledge is still limited and this gap is apparent in codes of practice. A European project focusing on robustness of steel and steel and concrete composite structures regarding the effects of impact recently started combining the 2 methods of residual strength and alternate load path. In the framework of the project activities, the Authors aimed their studies on the redundancy of the structure through slab-beam-systems and ductile joint as well as on the local behaviour of the impacted members. For this analytical, numerical and experimental investigations have been planned and executed. The paper describes the experimental activities related to the investigations on the structural redundancy and presents the preliminary test outcomes.

Keywords: Robustness, alternative load path, redundancy, steel and concrete composite structures, joint ductility, 3-D full-scale test, slab-beam-systems, steel joints, column bases, strain rate effect.

\section{Introduction}

Vulnerability of structures to progressive collapse and mitigation of the effects of local damages are topics widely discussed. The studies worldwide carried out allowed identifying two main design strategies: structural design based on certain levels of the accidental actions or strategies focused on the mitigation of the damage caused by localised failures. The consequences that the structural failure might produce guides the selection to the most appropriate design approach.

Design against accidental actions is usually based on the residual strength or the alternate load path methods, and a combination of these strategies may lead to an especially effective and cost efficient design for progressive collapse mitigation by redistributing the loads within the structure. The continuity of the frame and of the floor enable development of membrane action. They hence represent essential factors contributionf to a robust structural response. Therefore, the investigation of robust design concentrates on the redundancy offered by the joints, including the column bases, and by the 3-D performance capabilities of the floor system.

A European project [1] focusing on robustness of steel and steel and concrete composite structures affected by impact is still ongoing, the key features of which are presented in a companion paper [2]. The main aim of the research proposal is the development and definition of a new combined robust design approach for impact loading and the derivation of design guidelines for advanced impact 
design of framed steel and steel-concrete composite structures. In the framework of the project the authors concentrated their studies on the redundancy of the structure through slab-beam-systems as well as by ductile joint design. At this aim, analytical, numerical and experimental investigations have been planned and executed.

The research project started from the "reference project" of a five-storey steel-concrete composite structure selected as case study. The overall geometry of the building consists of a total height of $18 \mathrm{~m}$ with an inter-storey height of $3.60 \mathrm{~m}$, and the plan dimensions are $34.2 \mathrm{~m}$ in the longitudinal direction and $11.4 \mathrm{~m}$ in the transverse direction. Two buildings have been designed differing only in the spans of the transverse bays: equal in length in the first case and unequal in the second one. The design was based on the relevant Eurocodes, and no seismic checks were carried out in order to decouple the issues of seismic and of robust design. In order to approximate real practice, the following was adopted: i) as to the materials, concrete C30/37, rebars grade B450C, structural steel grade S355, and bolts class 10.9; ii) a solid slab with a thickness of $150 \mathrm{~mm}$; iii) full shear connection between steel beams and slab; iv) beam-column composite joints (including joints to the external columns) with flush end-plate steel connections. Rolled sections IPE 240 and HEB 220 were selected for beams and columns, respectively. The sudden loss of the column was identified as the accidental load scenario. 2-D and 3-D substructures were extracted from the reference building and experimentally investigated with the purpose to get an insight into the mechanisms allowing the activation of the alternate load paths resources. A total of 8 tests were performed: 2 on 3-D fullscale specimens and 6 on 2-D systems. Tests on 2-D systems investigated the response of both 2-D composite beam systems and of the composite joints. Finally, impact tests on steel joints and column bases investigate the dynamic response of these key structural elements and on the possible development of strain rate effects.

The paper illustrates the main features of both the specimens tested and the experimental campaign. The preliminary results of the tests are presented and discussed.

\section{The 2-D response}

\subsection{General}

Within the European project [1] and an additional German project [3] eight experiments on beamto-column joints were executed at University of Stuttgart. Within these tests the deformability and the ductility as well as the behaviour of the composite joint under combined bending and tensile load have been investigated. Additionally the influence of a high loading speed, resulting from a sudden column loss due to an impact, was considered. Furthermore two tests on 2-D frames were executed aiming at the investigation of the development of the catenary action after a column loss within the two-dimensional structure. The dimensions of the test specimens were extracted from the reference structure in order to get the same dimensions for all the test specimens within the project in order to have comparable test results.

\subsection{Experimental investigations on composite beam-to-column joints}

Within the composite joint tests a configuration with positive moment at the joint (JT 1) as well as a configuration with negative moment at the joint (JT 2) were tested. Therefore it was possible to investigate the directly affected joint above the column loss as well as the indirectly affected joint at the beam end next to the lost column. For the joints with positive bending moment (JT 1; see Fig. 1) as well as for the joints with negative bending moment (JT 2; see Fig. 2) four different tests have been performed respectively:

- JT 1.1 / 2.1: vertical load and normal load applied successively;

- JT 1.2 / 2.2: vertical load and normal load applied simultaneously with $1 \mathrm{~mm} / \mathrm{min}$;

- JT 1.3 / 2.3: vertical load and normal load applied simultaneously with $140 \mathrm{~mm} / \mathrm{min}$;

- JT 1.4 / 2.4: vertical load and normal load applied simultaneously with $70 \mathrm{~mm} / \mathrm{min}$.

The higher speed loads, chosen for the second part of the tests, resulting from the assumption that a column loss is in reality a dynamic failure. The real speed that occur at the top of the column have to be obtained out of impact tests on the column. The experimental tests on the behaviour on the column performed within the project are reported in [4].

For all the tests a failure of endplate in bending with failure mode 2 (bolt failure with yielding of the endplate) occurred as it was calculated in advance. Within the negative moment joint tests additionally the rebars failed which was also intended. From the results of the composite joint tests under 
combined bending and tension exposure it can be concluded that the transition from pure bending state up to a membrane state in the joint is possible.

The resistances calculated for the design of the joint specimens considering already over-strength effects could be exceeded within the experimental tests. The influence of the load speed with which the load was applied on the rotation capacity of the joint was in fact low.
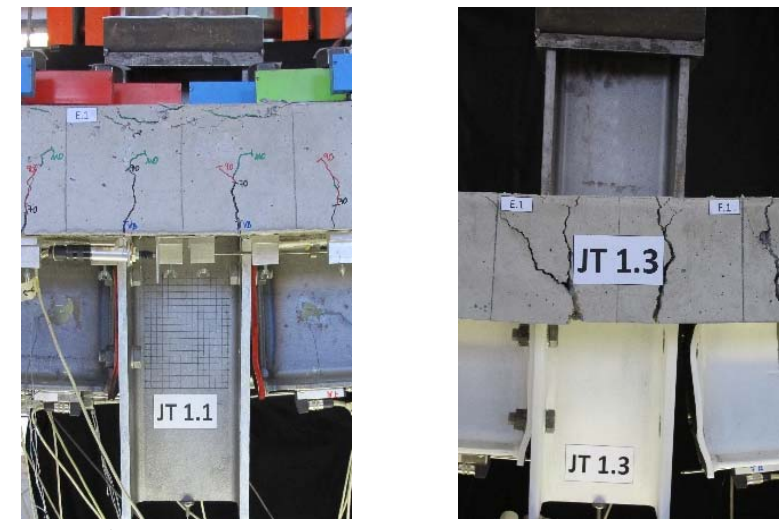

Fig. 1: Positive moment joint tests.
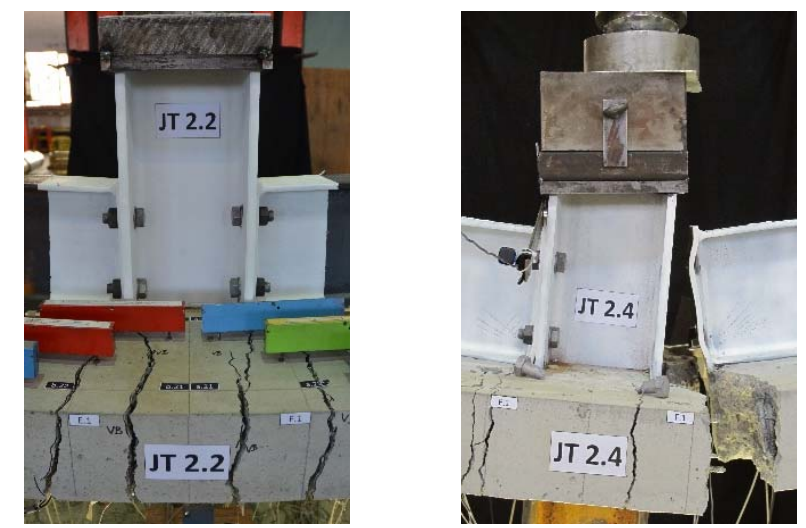

Fig. 2: Negative moment joint tests.

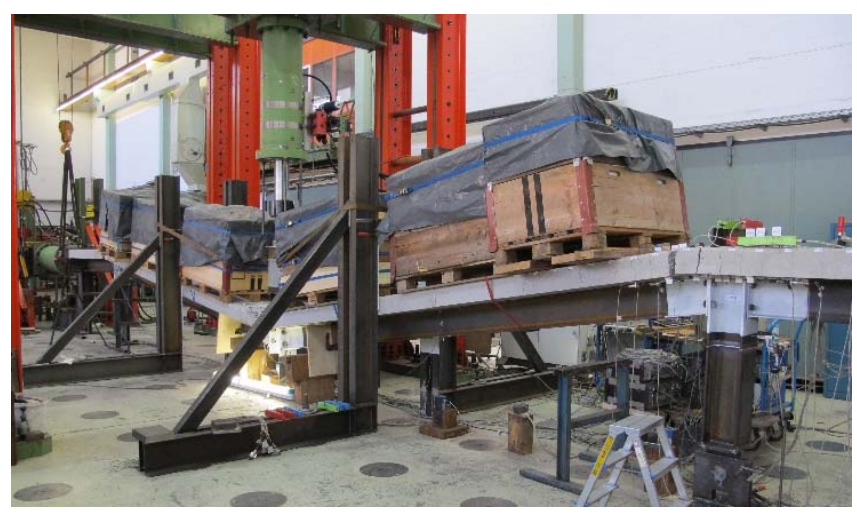

Fig. 3: Deformed 2D frame test FT 2.

\subsection{Experimental investigations on 2D frames}

In order to simulate the load history developing before and during the loss of a column, 2$\mathrm{D}$ frame tests were performed according to the following procedure: in a first step a uniformly distributed preload was applied simulating the reaction of the variable loads and the concrete slab on the beam. In a second step the central column of the frame was removed to observe the free deflection of the joint. Additionally further deformation was applied on the joint through a vertical force on the central column. When reaching large deformation of the middle column a tension band should be activated and additional horizontal force be applied on both sides of the test specimens in order to simulate the undamaged part of the building as it is explained in [2]. Within experimental tests in an earlier RFCS project "Robustness" [5] the activation of catenary action could be obtained with different dimensions of the test specimens and joint layout.

As in the first Frame Test (FT 1) the activation of catenary action could not be achieved the configuration of the second 2-D-frame test was modified so that larger bolts were used and the distance of the bolts to the web of the beam was increased in order to reach a higher rotation capacity of the joints. Hence in FT 2 due to ductile design of the joint with sufficient rotation capacity it was possible to activate the normal force to enable large deformations (see Fig. 3). The deformations developed at the external (negative moment) and at the internal (positive moment) joint are shown in Fig. 4. While failure of the rebars at the external joints occurred during the test (FT 2), there was no failure at the steel members of the joints until the end of the test.

The effect of catenary action is shown within the load-displacement-curve of the middle column in Fig. 5 where the activation of tension band is represented. Through the activation of the normal force at $360 \mathrm{~mm}$ deflection it was possible to increase the applied vertical load of the system. The test showed that large ductility and residual resistance remained in the system even when the concrete slab and the rebars failed, however the pure steel joint allowed increasing the rotations and developing membrane forces.

\subsubsection{Further investigations}

In further investigations it is necessary to perform numerical recalculations of the experimental investigation in order to receive detailed information on the precise behaviour of the composite joint and to increase the number of parameters influencing the composite joint behaviour. 

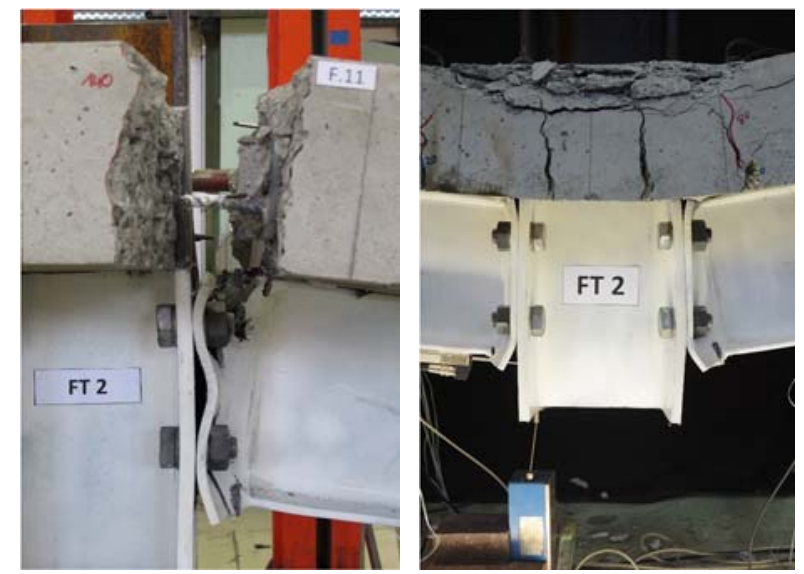

Fig. 4: Deformed ext. and int. joint of FT.

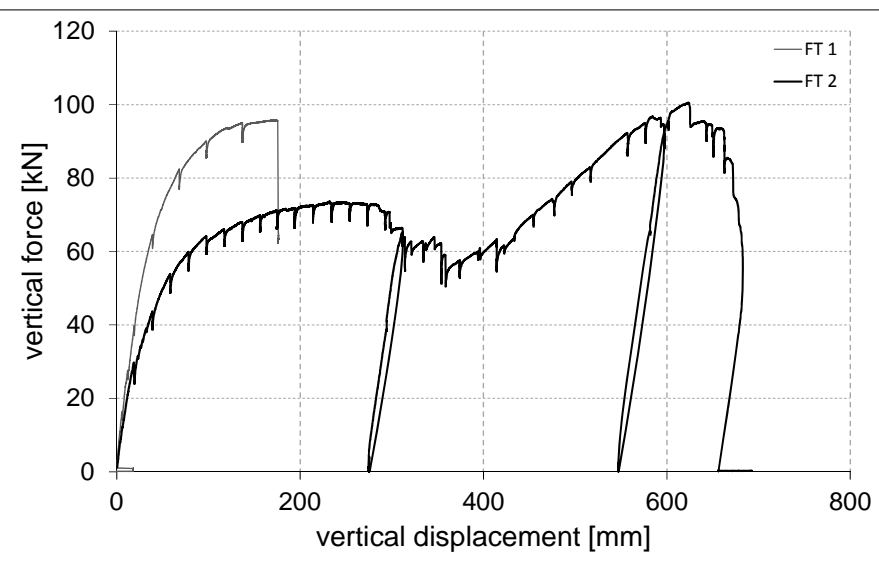

Fig. 5: Load-displacement-curve at middle column

\section{The effect of impact}

Within the project [1], 44 experimental impact tests are performed at the University of Liege:

- 22 tests on steel beam-to-column joints;

- 22 tests on column base joints.

The objective through the performed tests is to investigate the response of different joint components under impact loading, for different levels of energy (small, medium and high levels), and to compare this response to the one obtained through a static test to highlight the possible dynamic effects and, in particular, the possible strain rate effects. Also, the obtained results will be used for the validation of analytical models to predict the dynamic response of joints which are under development.

The following joint components are investigated within the conducted test campaign:

- For the beam-to-column joints:

0 the end-plate in bending (EPB);

0 the column flange in bending (CFB);

0 the beam flange in compression (BFC);

o the column web in compression (CWC).

- For the column base joints:

o the concrete block under tension with ductile or non-ductile failure modes;

o the end-plate in bending.

For the beam-to-column joint tests (see the testing setup in Fig. ), an actual joint configuration (called "real joint") has been designed first. Then, starting from this real joint, modifications have been made to "isolate" the components to be tested and to observe the failure mode associated to the studied components. Accordingly, 5 different specimen configurations have been designed (1 for the real joint and 4 for the different components to be tested).

However, some properties are common to all the tested beam-to-column joints:

- used profiles: S355 IPE180 for the beams and S355 HEB140 for all the other columns;

- the length of the beams is governed by the dimension of the used testing machine, knowing that the spacing of the beam support is equal to $1.6 \mathrm{~m}$;

- the web stiffeners placed on the beam, at the position of the beam supports, to avoid the buckling of the web under the associated concentrated loads;

- a 50mm thick plate was placed at the top of the column, where the mass impacted the specimen, to redistribute the impact load within the column;

- the welds have been designed to be full strength (for S355): a > 0.55t with a, the throat radius of the weld and $t$, the maximum thickness of the assembled plates;

- when bolts are used, they are placed with the same pitching. 


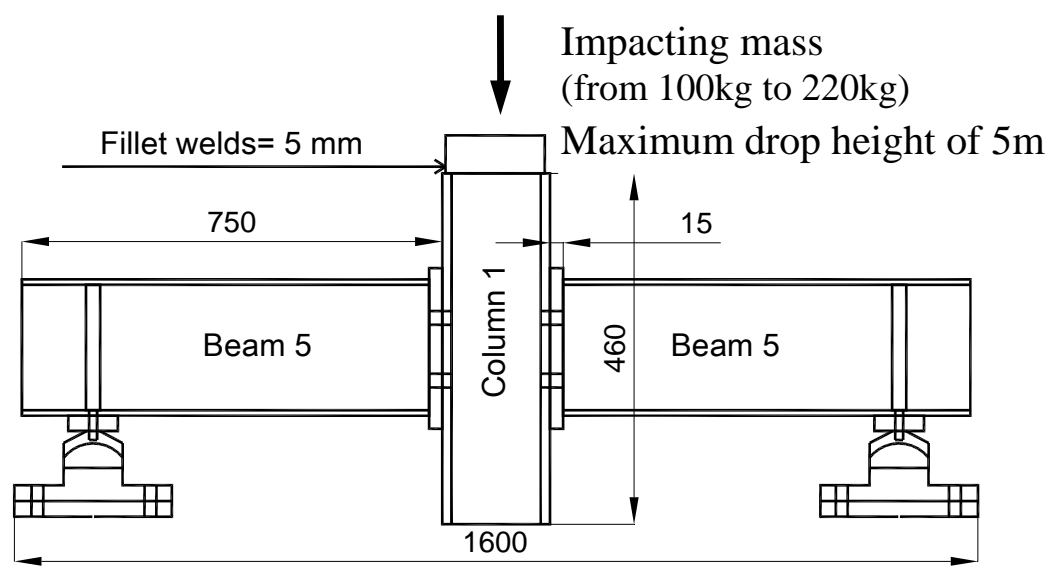

Fig. 6: Global configuration and testing setup for the beamto-column joints .

For the measurements during the impact tests, two sets of two high speed cameras have been used to measure the global displacement of the specimens and the deformation of some specific parts of the tested specimens.

In Fig. 7, first results may be observed. It can be seen on this figure that for the joint component "Beam flange in compression", no strain rate effects are observed as the loads associated to the maximum displacements observed during the impact tests correspond exactly to the static response while for other components, such as the "column web in compression", significant strain rate effects are observed as the loads associated to the maximum displacements is higher than the ones observed through the static response.
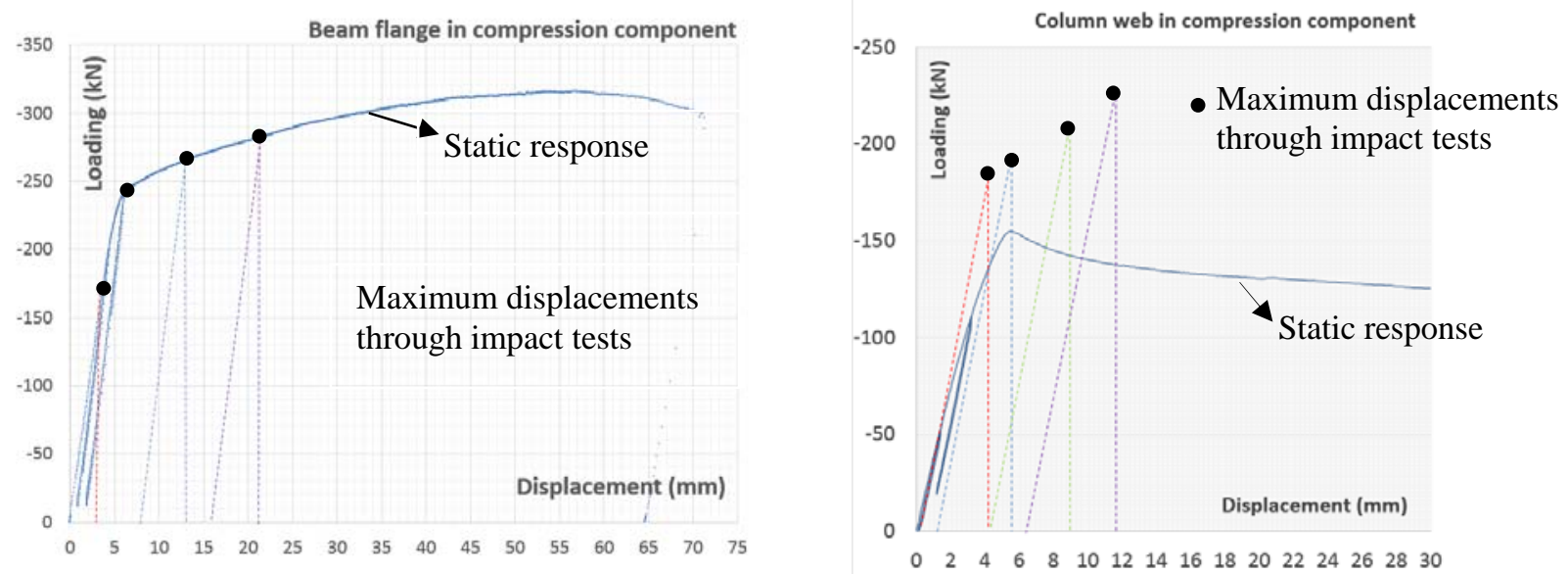

Fig. 7: First experimental results for the beam-to-column joint tests - Applied load vs. vertical displacement of the column.

For the column base joints, it is also intended to test the behaviour of different joint components under impact:

- the concrete block under tension with a ductile failure mode (using 1 stirrup or 2 stirrups);

- the concrete block under tension with a non-ductile failure mode and no stirrups;

- the end-plate in bending.

For these specimens, the global configuration of the column base to be tested has been proposed by the University of Stuttgart. The tested joint configuration and the testing setup is given in Fig. 8 . The test campaign is still under progress and results are not yet available.

$\mathrm{L}>1100 \mathrm{~mm}-\mathrm{H}>400 \mathrm{~mm}-\mathrm{W}>1000 \mathrm{~mm}$
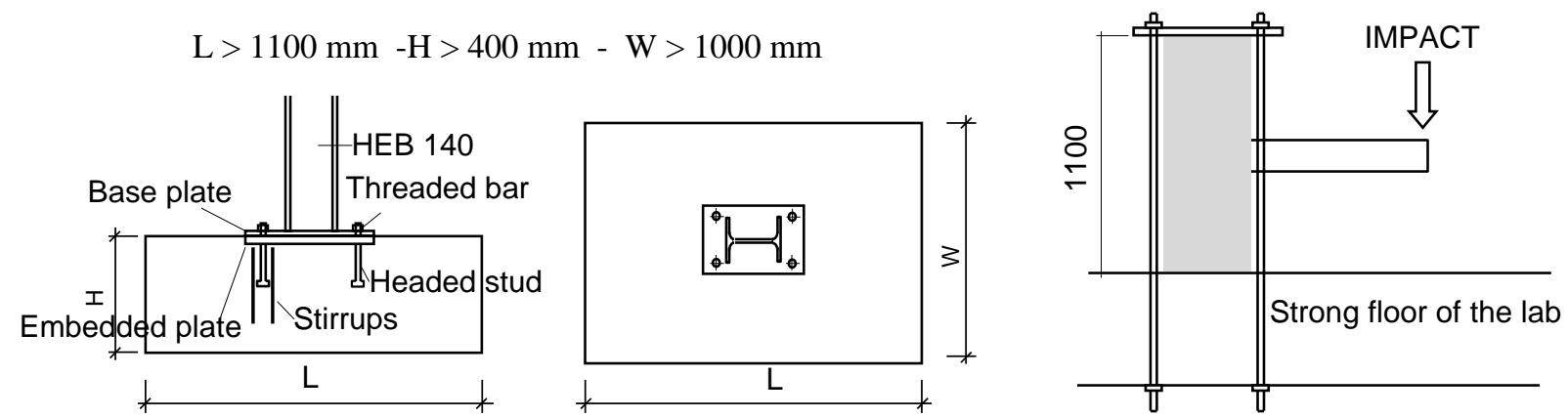

Fig. 8: Tested joint configuration (with two stirrups) and testing setup. 


\section{The 3-D response}

\subsection{General}

The experimental contribution of the University of Trento to the project [1] aims at investigating on the redundancy contribution offered by the floor system and the framed structure including the joints and column bases. For this aim two tests on substructures representative of the first floor of the reference building, assumed as case studies, were planned. Fig. 9, which shows the floor plans of the two specimens (see the blue dotted squares), allows identifying the position of the specimens with respect to the full framed structures. In both the tests the collapse of the central column (highlighted with a red circle in the figure), is simulated.
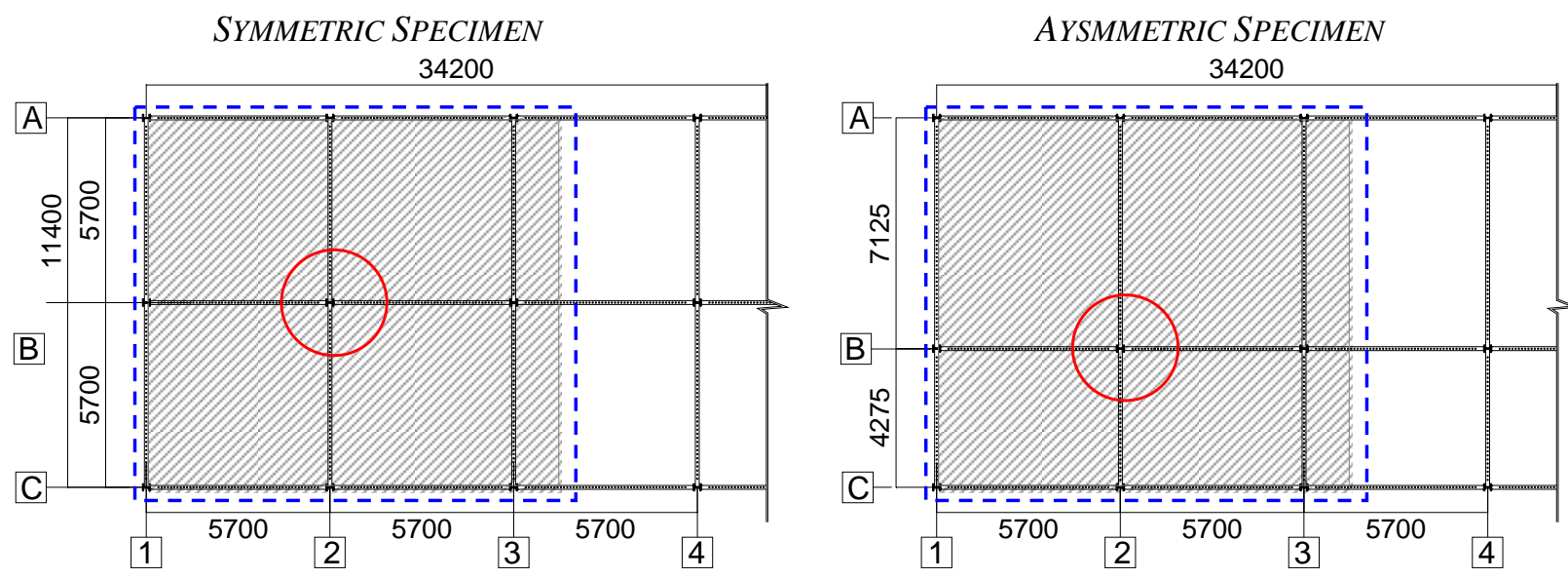

Fig. 9: The full-scale specimens (plan view - measures in $\mathrm{mm}$ ).
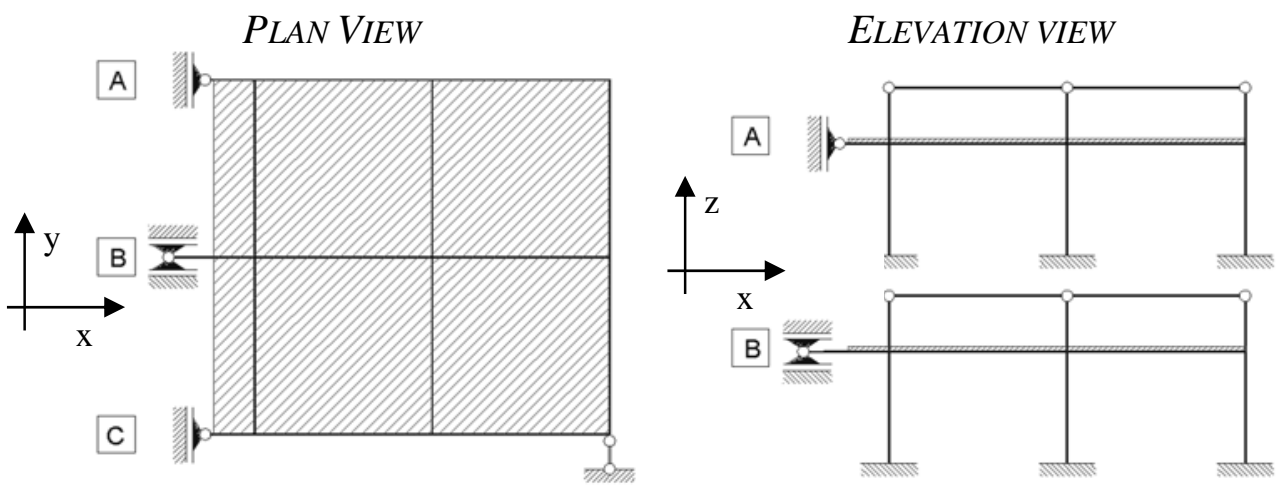

In order to analyse substructures representative of the reference building, a detailed design of suitable restraints of the specimens was required. The restraints in fact assume the key role to simulate the presence of the remaining part of the structure. For the prediction of the be-

Fig. 10: The restraints of the symmetric specimen.

haviour, refined Finite Element Models of the full-frames and sub-frames were developed by using the Abaqus program. The analyses, which simulated the test's conditions, allowed identifying the boundary restraint conditions shown in Fig. 10. The details and outcomes of these preliminary analyses are reported in [6].

The planned 'loading' sequence consists of three steps. In the first step, the factored vertical design load is applied onto the slab, so defining the condition before the column's collapse, in the second step the 'central column' is gradually 'removed' simulating the column collapse in consequence of an accidental action. In order to get an appraisal of the available safety margin, as a third step, a tension force is applied at the lost column location and increased until a substantial distress of the system is observed.

\subsection{The catenary and the slab action}

The test on the symmetric specimen was already performed, while the second test is in progress. The results presented in the following are hence related to the symmetric specimen.

Fig. 11 illustrates the specimen at the end of its construction and after the application of the load onto the slab. As it can be observed in the figure on the right, the load was simulated with sacks filled with sand reproducing a uniform distributed load of $8,8 \mathrm{kN} / \mathrm{m}^{2}$. The central column was simu- 
lated by means of a hydraulic jack which, during the 'constructional phases', was held in place in a non-operating state. The central beams were hence held in position by means of props which were removed just before the beginning of the test.

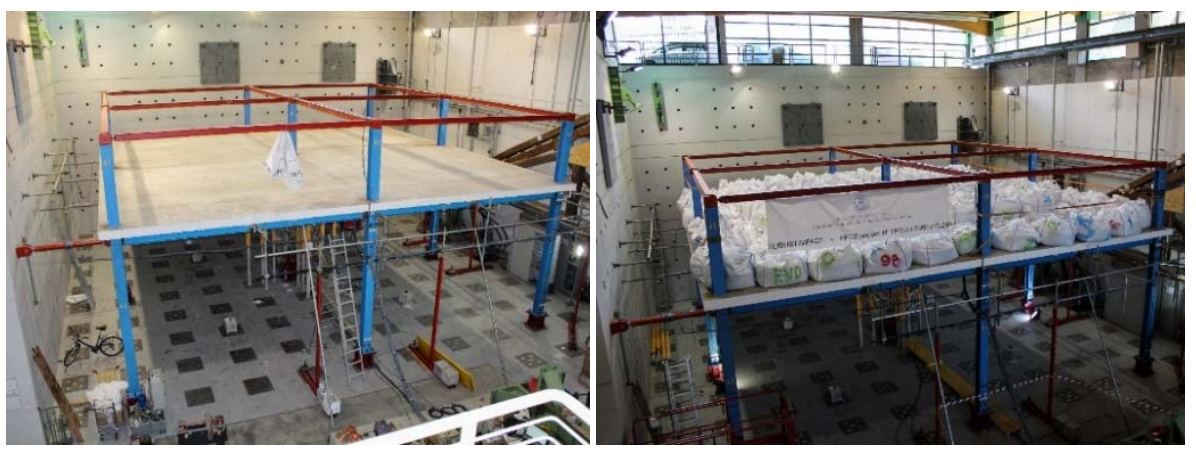

Fig. 11: The specimen of the symmetric frame.
The considerable amount of parameters affecting the response required an accurate selection of the quantities to be measured. The attention was mainly focused on the response of columns, beams and beamto-column joints. During the test, all the instruments' signals, including the load cell connected to the hy-

draulic jack, were logged with a frequency of $2 \mathrm{~Hz}$.

The test comprised the following phases:

1- "Activation" of the hydraulic jack and removal of the props. The load measured by the loading cell was of $228 \mathrm{kN}$ and represents the self-weight portion of the specimen sustained by the central column;

2- Application of the vertical load to the slab. At the end of this phase the load applied to the central column was of $668 \mathrm{kN}$;

3- Gradual removal of the column simulated by reducing the pressure of the hydraulic jack down to zero. The vertical displacement of the central joint was of about $157 \mathrm{~mm}$;

4- Stabilization of the specimen with the vertical displacement of the central joint increasing to 163mm;

5- Application of a tensile force increasing up to the end of the test. The final tension load was of $300,9 \mathrm{kN}$ and the vertical displacement was $305 \mathrm{~mm}$.

Fig. 12 illustrates the deformation of the specimen at the end of the test (Fig. 12a) and the loadcentral joint vertical displacement relation (Fig. 12b). At a load of 286,8kN in tension the collapse of a bolt of the bottom row of a connection at the central column took place (Point A in Fig. 12b). The test continued up to a load of $300,9 \mathrm{kN}$ when the second bolt in the same row fractured (point B in Fig. 12b).
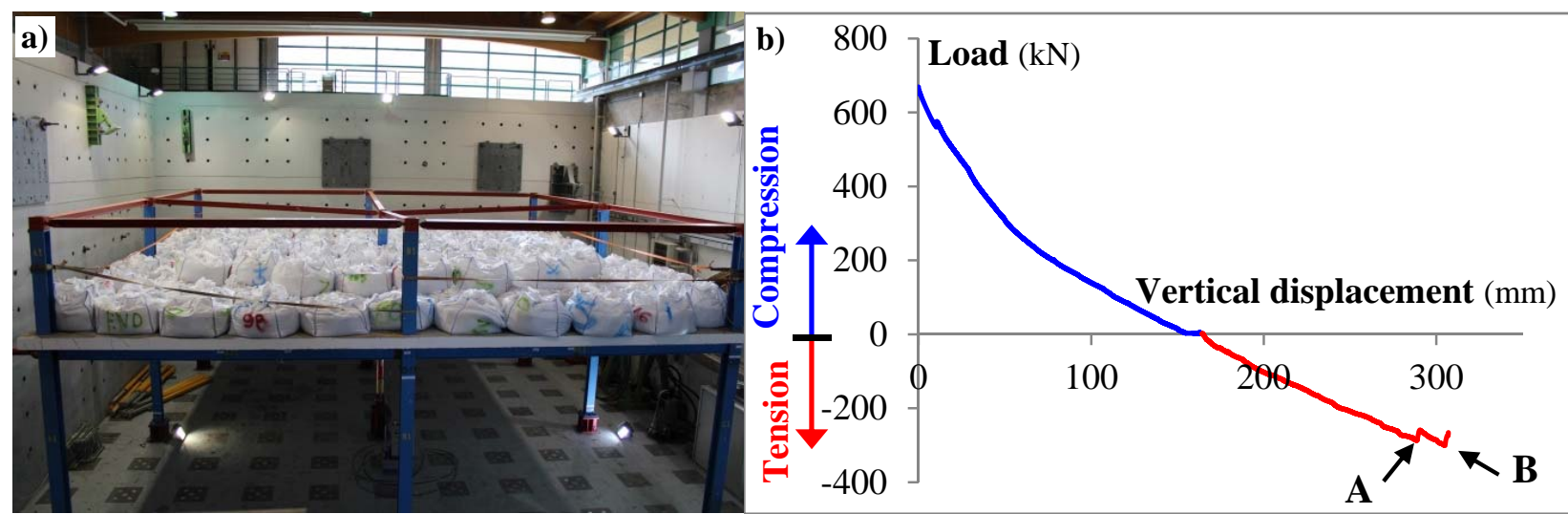

Fig. 12: a) Specimen at the end of the test; b) Load-displacement curve of the central column.

The visual inspection of the specimen allowed identification of significant deformations of the external columns mainly concentrated at the beam-to-column joint. A concentrated 'rotation' of the column revealed the plastic shear deformation of the columns web panel. Furthermore, the mechanism of force transmission between column and beam induced compression at the beam lower flange with associated instability phenomena. Horizontal cracks developed in the slab over the

thickness on the outer side of the slab at external columns associated with the transmission of shear forces between concrete slab and column. As to the crack pattern (Fig. 13), the evolution observed at the bottom side of the slab confirmed the stress distribution calculated by numerical analysis. 

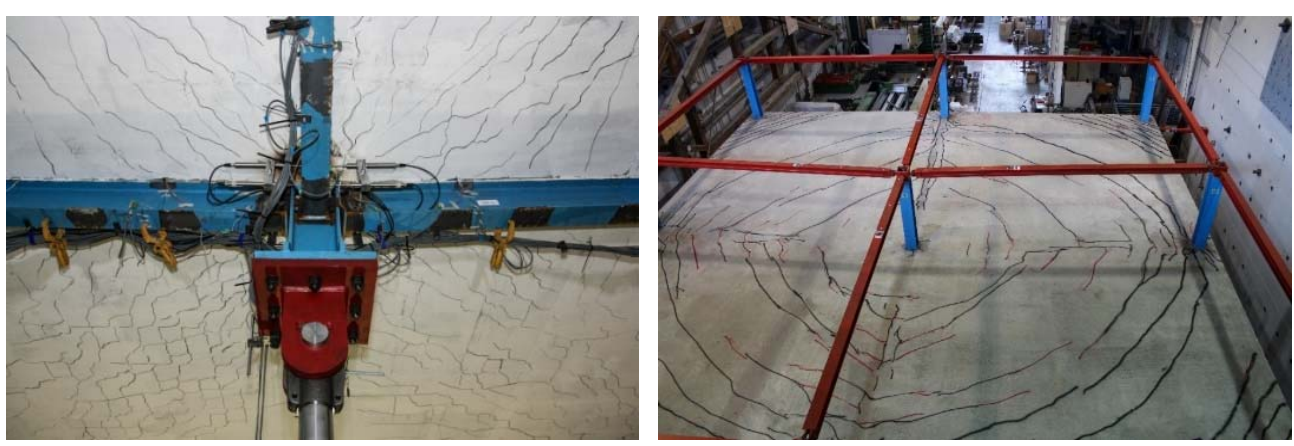

Fig. 13: Slab crack pattern at the end of the test.

also confirmed to play an important role.

\section{Summary and conclusions}

A European project [1] focusing on robustness of steel and steel and concrete composite structures recently started aiming at contributing to the development of a combined robust design approach for impact loading. In the framework of this research project the authors mainly concentrated on their research on the redundancy of the structure through slab-beam-systems as well as by ductile joint design. A wide experimental campaign was hence planned which comprises tests on 3-D full-scale specimens and on 2-D composite beam systems and composite joints systems. Moreover, in order to investigate on the dynamic response of key structural elements and on the possible development of strain rate effects, impact tests on steel joints and column bases were also planned. The preliminary results of the tests, which are still in progress, allow pointing out the moderate influence of strain rate on both the beam-to-column joints and on the main joint components. 2-D and 3-D tests' results pointed out the potential robustness ensured by the membrane action developed by the flooring and the framed system. The important role of the ductility of the beam-to-column joints has also been confirmed.

\section{Acknowledgement}

The work presented here is carried out as a research project [1] by different European partners with a financial grant from the Research Fund for Coal and Steel (RFCS) of the European Community. The authors gratefully acknowledge the financial support.

\section{References}

[1] KUHLMANN U. et al., "ROBUSTIMPACT Robust impact design of steel and composite structures”, RFSR-CT-2012-00029 (running).

[2] HOFFMANN N., KUHLMANN U., DEMONCEAU J.-F., JASPART J.F., COLOMER C., HOFFMEISTER B., ZANDONINI R., HJIAJ M. and MOHLER C., "Robust impact design of steel and composite building structures", Proceedings of IABSE Workshop, February 11-12, 2015, Helsinki , Finland, (in print).

[3] KUHLMANN U., HOFFMANN N., “Außergewöhnliche Bemessungssituationen nach DIN EN 1991-1-7 - Effektive Anwendung und Bemessungsstrategien für Stahl- und Verbundrahmentragwerke”, DASt/AiF research project, No. 17153.

[4] KORNDÖRFER J., HOFFMEISTER B., FELDMANN M., HENG P., HJIAJ M., "Robust impact design of steel and composite building structures: Advances in the Residual Strength Method”, Proceedings of IABSE Workshop 2015, Helsinki, February 2015

[5] KUHLMANN U. et al., "ROBUSTNESS Robust structures by joint ductility”, Final Report, Contract-No. RFS-CR-04046, 2008.

[6] ZANDONINI R., BALDASSINO N. and FREDDI F., "Robustness of flooring systems in 3-D frames. An experimental assessment", Proceeding of $7^{\text {th }}$ European Conference on Steel and Composite Structures (EUROSTEEL), September 10-12, 2014, Naples, Italy, pp. 481-487. 